\title{
ENZYMATIC AND METABOLIC STUDIES WITH ALLOPURINOL
}

\author{
BY
}

\author{
GERTRUDE B. ELION
}

Tuckahoe, New York, 10707, U.S.A.

Since the effectiveness of allopurinol as a xanthine oxidase inhibitor in vivo is the subject of this symposium, it seems appropriate to consider the nature of this inhibition in vitro and to examine the characteristics of distribution, clearance, and metabolic conversion of the drug which may add to or detract from its activity.

The most readily available source of xanthine oxidase, and the most convenient for studies in vitro, is cow's milk. It was thus important to determine whether the kinetics of the inhibition of this enzyme was the same as for the liver enzyme of other species, particularly man. Extracts of mouse and human liver were prepared and the xanthine oxidase in the $40,000 \mathrm{G}$. supernatant fractions was partially purified by ammonium sulphate fractionation. The enzymes from the three sources (cream, mouse liver, human liver) were found to be identical with respect to $p \mathrm{H}$ optima ( $p \mathrm{H} 8 \cdot 0-8 \cdot 4)$. However, in order to approximate physiological conditions more closely, most of the inhibition studies to be reported here were done at $p \mathrm{H} \mathrm{7.4}$. At this $p \mathrm{H}$, in $0.05 \mathrm{M}$ phosphate buffer at $25^{\circ} \mathrm{C}$., there were some small differences in the binding constants of the three enzyme preparations for xanthine, the mouse liver enzyme having the highest $\mathrm{K}_{\mathrm{m}}$ (Table) (cf. Elion, Taylor, and Hitchings, 1964). The values for the cream and human liver enzymes $\left(\mathrm{K}_{\mathrm{m}}=4 \times 10^{-6}\right.$ and $K_{m}=3 \times 10^{-6} \mathrm{M}$ respectively) are similar to that reported by Fridovich and Handler (1958b) for the cream enzyme $\left(\mathrm{K}_{\mathrm{m}}=2.65 \times 10^{-6} \mathrm{M}\right)$ under the same conditions. ${ }^{1}$ The $K_{m}$ of xanthine for human liver xanthine oxidase does not change appreciably between $p \mathrm{H} 7 \cdot 4$ and $p \mathrm{H} 8$, but increases 10 -fold at $p \mathrm{H} 8 \cdot 6$ (Table).

\footnotetext{
1 The value for $\mathrm{Km}$ reported by Watts, Watts, and Seegmiller (1965) for human intestinal xanthine oxidase, $K_{m}=1.55 \times 10^{-6} \mathrm{M}$, is in good agreement with those reported here, since their studies were carried out at $\mathrm{pH} 8.3$ (pyrophosphate buffer, $37^{\circ} \mathrm{C}$ ) falls between those found at $p H \mathrm{H} .0$ and $p \mathrm{H} 8.6$ for the human liver enzyme (see Table).
}

TABLE

MICHAELIS CONSTANTS FOR XANTHINE OXIDASES FROMCS DIFFERENT SPECIES

\begin{tabular}{|c|c|c|c|c|}
\hline Source & $p \mathbf{H}$ & $\underset{\mathbf{K}_{\mathbf{m}}}{\text { Xanthine }}$ & $\underset{\mathbf{K}_{\mathbf{i}}}{\text { Allopurinol }}$ & $\underset{\mathbf{K}_{\mathbf{i}}}{\text { Allo-xanthine }}$ \\
\hline Bovine Cream & $7 \cdot 4 a$ & $4.0 \times 10^{-6}$ & $7.0 \times 10^{-1}$ & $6.3 \times 10^{-6}$ \\
\hline Mouse Liver & $7 \cdot 4 a$ & $1 \cdot 3 \times 10^{-5}$ & $3.2 \times 1 C-7$ & $1.2 \times 10^{-6}$ \\
\hline $\begin{array}{l}\text { Human Liver } \\
\text { Human Liver } \\
\text { Human Liver }\end{array}$ & $\begin{array}{l}7 \cdot 4 \mathrm{a} \\
8 \cdot 0 \mathrm{~b} \\
8 \cdot 6 \mathrm{~b}\end{array}$ & $\begin{array}{l}3.0 \times 10^{-6} \\
3.7 \times 10^{-6} \\
4.1 \times 10^{-5}\end{array}$ & $\begin{array}{l}1.9 \times 10^{-7} \\
1.0 \times 10^{-7} \\
2.0 \times 10^{-7}\end{array}$ & $\begin{array}{l}1.1 \times 10^{-6} \\
3.6 \times 10^{-3}\end{array}$ \\
\hline
\end{tabular}

In $0.05 \mathrm{M}$ phosphate or Tris- $\mathrm{HCl}$ buffer, $25^{\circ} \mathrm{C}$. In $0.05 \mathrm{M}$ Tris- $\mathrm{HCl}$ buffer, $25^{\circ} \mathrm{C}$.

The Lineweaver-Burk plots $(1 / \mathrm{v}$ v. $1 / \mathrm{s})$ for $\mathrm{fin}$ inhibition by allopurinol, with xanthine as sutostrate, showed the kinetics of a typical competitive inhibition for each of the enzymes. The data for thes human liver enzyme are shown in Fig. 1 (opposite).

Allopurinol (HPP) is not only an inhibitor of, but also a substrate for, xanthine oxidase, and the pro- $\frac{\mathbb{Q}}{2}$ duct of its oxidation, allo-xanthine (DHPP) a xan- $=\vec{F}$ thine analogue, is also an inhibitor of the enzyme. $\frac{3}{3}$ As will be discussed shortly, the nature of the inhibition by allo-xanthine is quite different from that by allopurinol. The inhibition constants for both HPP and DHPP for the three enzymes at $p \mathrm{H} 7 \cdot 4$ at $25^{\circ} \mathrm{C} . \overline{\mathrm{a}}$ are given in the Table. ${ }^{2}$ Allopurinol is five to teno times as potent an inhibitor as DHPP and is bound to the human enzyme fifteen times as well as theô substrate xanthine. At $p \mathbf{H} 8.0$ the $\mathrm{K}_{\mathrm{i}}$ for HPP is $₹$ 37 times lower than the $K_{m}$ for xanthine, while ato $p \mathrm{H} 8.6$ it is 200 times lower.

Although allopurinol behaves like a typical com- $\frac{D}{2}$ petitive inhibitor when the enzyme studies are conducted by mixing substrate and inhibitor and then adding the enzyme to start the reaction, quite a 0 different situation obtains if the inhibitor is incubated with the enzyme before the addition of substrate.

The $\mathrm{K}_{\mathrm{i}}$ for allopurinol was erroneously reported earlier (Elion and others, 1964) to be $4.4 \times 10^{-0} \mathrm{M}$. 


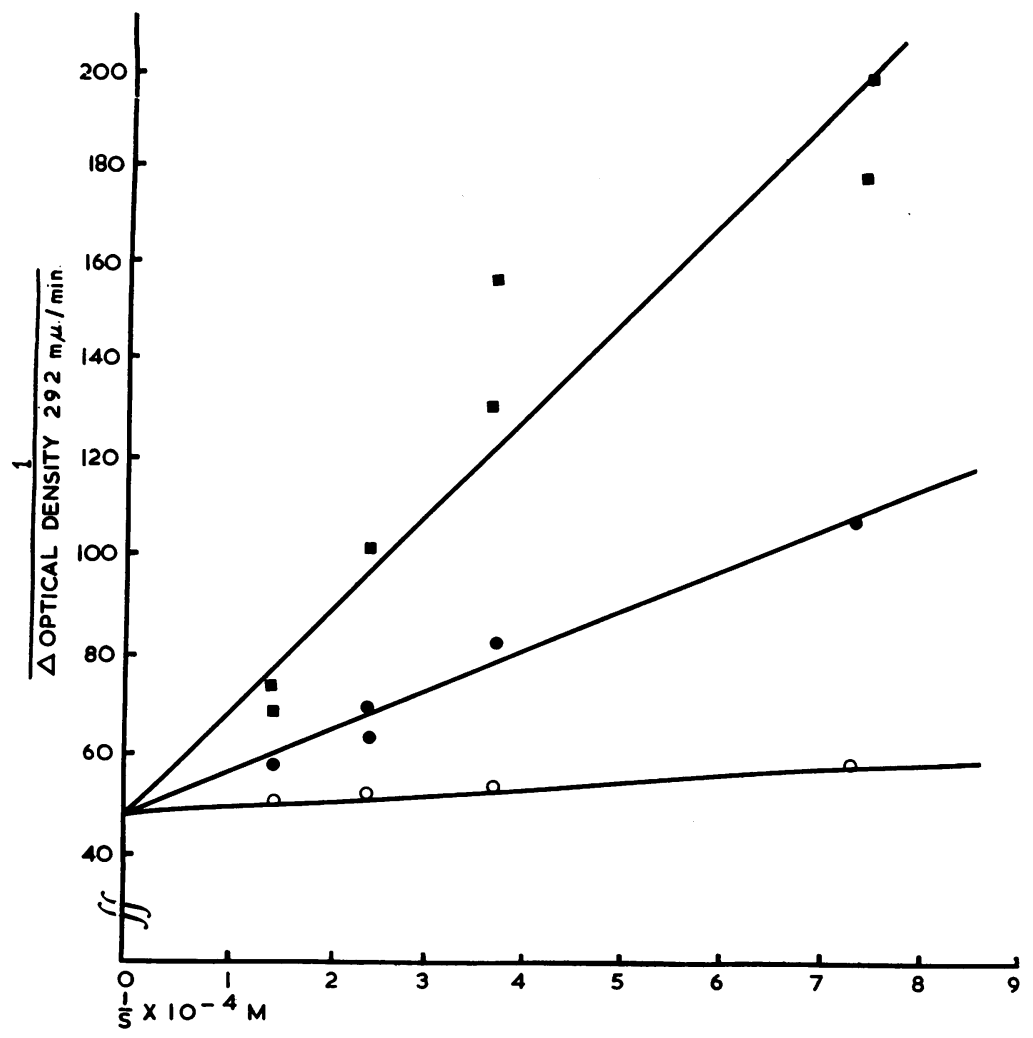

Fig. 1.-Lineweaver-Burk plot $\frac{1}{\mathrm{v}} v$. $\frac{1}{\mathrm{~s}}$ for the inhibition of human live xanthine oxidase by allopurinol (HPP), $p \mathrm{H} 7 \cdot 4$ at $25^{\circ} \mathrm{C}$.

, xanthine alone;
, xanthine $+0.98 \times 10^{-6} \mathrm{M}$ allopurinol;

, xanthine $+2.92 \times 10^{-6} M$ allopurinol.

A pre-incubation of even a few minutes may lead to an almost complete inactivation of the enzyme (Elion, Taylor, and Hitchings, 1966b). In an AckermanPotter plot, where velocity is plotted against amount of enzyme, the effect of pre-incubation of enzyme and inhibitor is very apparent. In Part A of Fig. 2 (overleaf), HPP and enzyme were pre-incubated for 10 minutes before the addition of substrate. The kinetics are those of a pseudo-irreversible inhibitor, which suggests that the inhibitor is bound so tightly to the enzyme that it is not displaced at a measurable rate by the substrate. Since dialysis restores the activity of the enzyme, the inactivation is not due to alteration of the enzyme. When the substrate and inhibitor were present before the enzyme was added (Part B, Fig. 2), the kinetics appeared to be competitive. The "inactivation" of the enzyme by HPP in the absence of substrate may not have physiological significance since the substrate is already present in vivo, but this is a point which must not be overlooked when determining the inhibitory effectiveness of this substance in vitro.

Another interesting and perhaps more unusual aspect of enzyme kinetics is illustrated by the behaviour of allo-xanthine with xanthine oxidase.
If one attempts to study the inhibition in the usual way, by measuring the initial rate of oxidation in the presence and absence of inhibitor, one encounters the problem of deciding just what this "initial rate" is. In the uninhibited system, the velocity of the reaction proceeds at a constant rate until the initial substrate concentration is appreciably altered, usually when about half of the xanthine has been oxidized. This is also true when the enzyme is inhibited by allopurinol. With allo-xanthine, however, the rate of xanthine oxidation decreases progressively and, by manipulating the concentration of enzyme and inhibitor appropriately, one can arrive at a point where the oxidation comes to an almost complete standstill long before there is appreciable substrate depletion. This is perhaps best illustrated by a tracing (Fig. 3, overleaf) of the continuous change in the optical density at $292 \mathrm{~m} \mu$ measured in a Cary spectrophotometer, in the uninhibited system and in the presence of allo-xanthine. When fresh enzyme was added to the uninhibited system at the indicated points, oxidation resumed at an accelerated rate and the slowing-up process again occurred. This "inactivation" is not due to product inhibition, since the addition of uric acid has no 

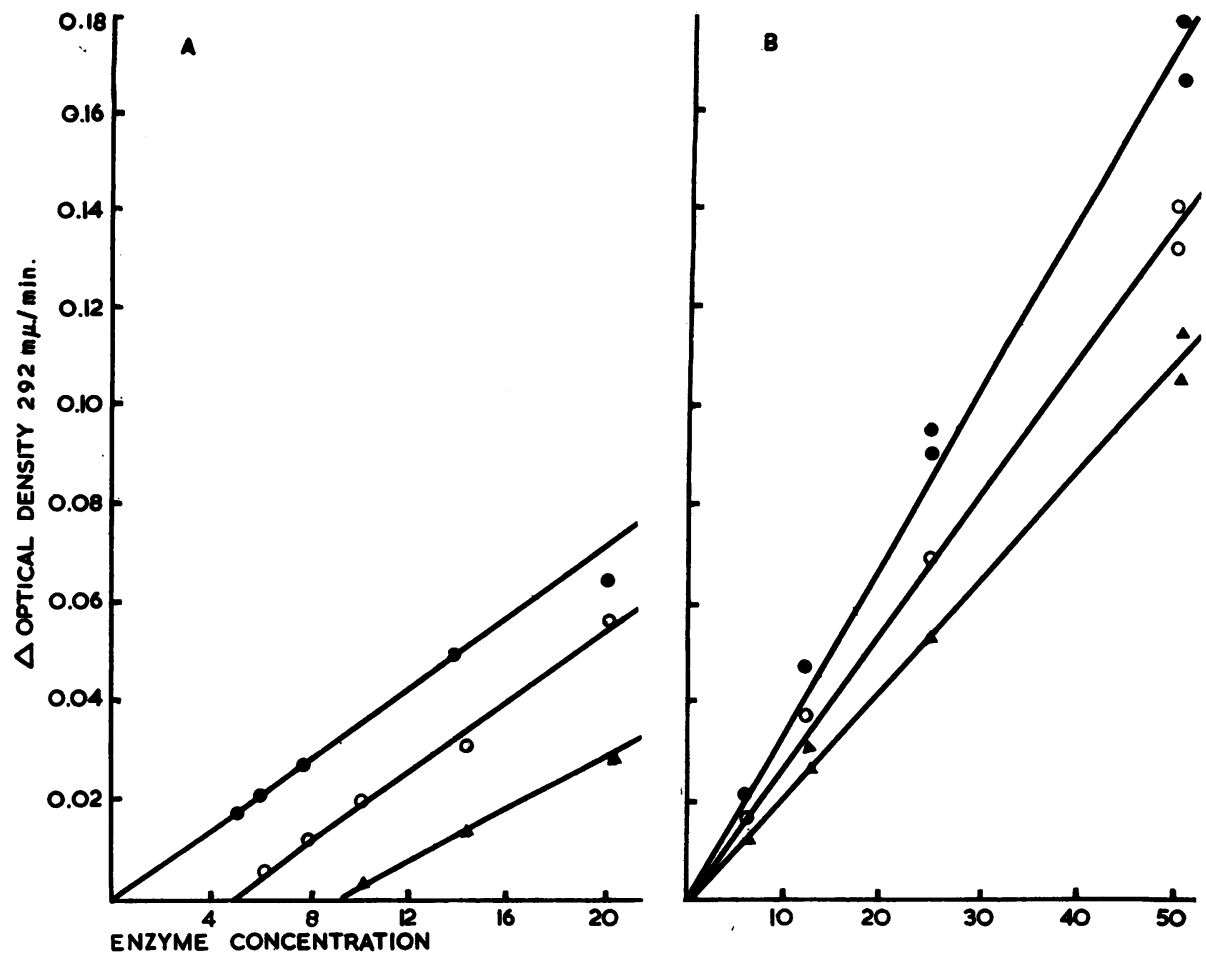

Fig. 2.-Ackerman-Potter plot (velocity $v$, enzyme concentration) for bovine milk xanthine oxidase inhibited by allopurinol, $\mathrm{pH} 7.4$ at $25^{\circ} \mathrm{C}$. under two sets of experimental conditions.

PART A: Enzyme was incubated with allopurinol for 10 minutes before addition of the substrate, xanthine.

O, xanthine $\left(4 \times 10^{-6} M\right)$;

$A$, xanthine $\left(4 \times 10^{-} M\right)+$ allopurinol $\left(2 \cdot 8 \times 10^{-0} M\right)$

PART B: Enzyme was added to a mixture of xanthine and allopurinol.

, xanthine $\left(4 \times 10^{-6} M\right)$;

, xanthine $\left(4 \times 10^{-3} M\right)+$ allopurinol $\left(1.5 \times 1 C^{-3} M\right)$

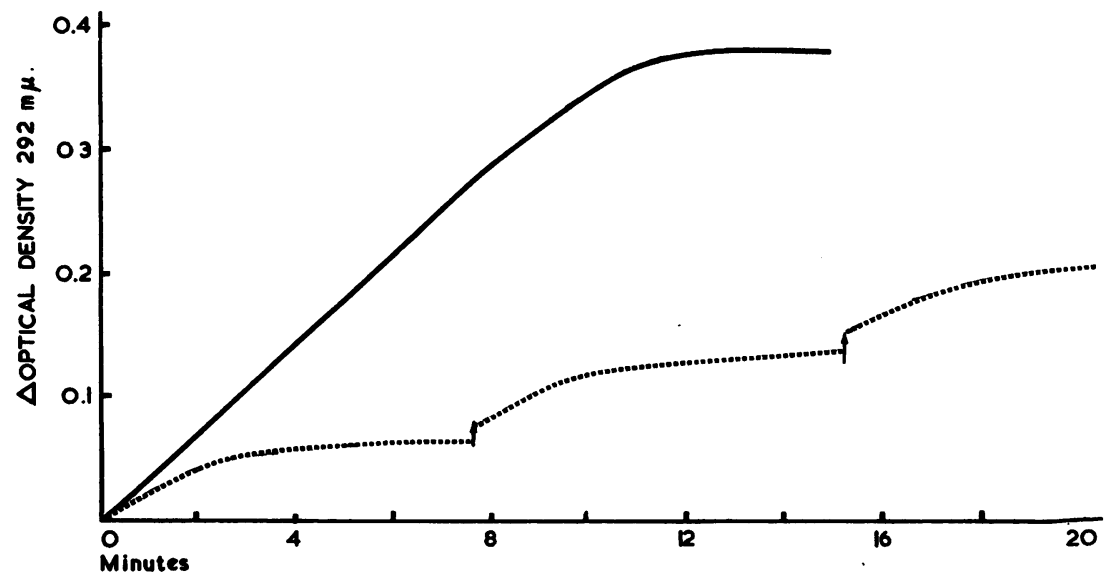

Fig. 3. - Change in optical density at $292 \mathrm{~m} \mu$. as a function of time in an uninhibited system and one inhibited with allo-xanthine. Each cell contains 3.4 units of milk xanthine oxidase and 300 units of catalase in a total volume of $3 \mathrm{ml}$. of Tris buffer, $p \mathrm{H} \mathrm{7.4}$ at $25^{\circ} \mathrm{C}$.

$-\ldots$, xanthine, $6 \mu \mathrm{g} . / \mathrm{ml}$.;

Optical densities were measured continuously in a Cary Model 15 spectrophotometer. At the times indicated by the arrows an additional 3.4 units of xanthine oxidase was added and readings were resumed within 30 seconds of the addition. 
effect, nor does it occur in the presence of inhibitor and enzyme alone, as determined by pre-incubation experiments (Elion and others, 1966b). One interpretation of these kinetics is that DHPP competes with xanthine for the enzyme per se in the initial time period, but that it then binds "irreversibly" to the enzyme substrate complex or to the enzyme which has been suitably altered by the substrate. Dialysis restores the activity of the enzyme. It is obvious that in a case such as this "initial velocity" has no real meaning. To obtain the $K_{i}$ values given in the Table, the rate during the first $1 \frac{1}{2}$ minutes was arbitrarily chosen. However, if one had chosen the overall velocity during the first 5 minutes, alloxanthine would appear as a much stronger inhibitor. Therefore, the comparison made above between the potencies of HPP and DHPP may not be valid.

Early experiments on the metabolic fate of allopurinol in mice showed it to be extensively oxidized in vivo to allo-xanthine. Both allopurinol and its metabolite were distributed in total body water, with the exception of brain tissue where the concentration was approximately one-half that in blood (Elion, Kovensky, Hitchings, Metz, and Rundles, 1966a). In the $\operatorname{dog}{ }^{14} \mathrm{C}$-allopurinol, given intravenously, disappeared from the plasma with a half-clearance time of 75 minutes (Fig. 4). This disposal represented a combination of excretion by the kidney and oxidation to allo-xanthine. By the end of 6 hours no allopurinol was detectable in the plasma and none appeared thereafter in the urine. The allo-xanthine formed was cleared more slowly, $t_{\frac{1}{2}}=4$ hours, and its clearance was calculated to be approximately one-half the rate of creatinine clearance. This relationship of the clearances of allo-xanthine and creatinine in the mongrel dog has been confirmed by recent experiments done in collaboration with Dr. T. F. Yü, using allo-xanthine infusions.

In man the clearance of ${ }^{14} \mathrm{C}$ from the plasma in Case 1 after an intravenous dose of ${ }^{14} \mathrm{C}$-allopurinol (Fig. 5, overleaf) was much slower than in the dog. After an initial rapid fall during the first hour, the half-clearance time was 14-16 hours. That this was not due to plasma protein binding was readily demonstrable by equilibrium dialysis (Elion and others, 1966a); neither allopurinol nor allo-xanthine shows any binding to plasma proteins. The cumulative urinary excretion of HPP and DHPP in the same patient after an intravenous dose of allopurinol is shown in Fig. 6 (overleaf). Very little free HPP was excreted between 6 and 12 hours and none thereafter. Allo-xanthine accounted for the bulk of the excreted radioactivity, even in the early urine collections. By the end of 24 hours, 57 per cent. of the ${ }^{14} \mathrm{C}$ had been excreted, 48 per cent. as DHPP and 9 per cent. as HPP. During the 12 to 24 -hour time period, when all of the ${ }^{14} \mathrm{C}$ in the plasma was in the form of DHPP $(1.5 \mu \mathrm{g} . / \mathrm{ml}$.$) , the clearance of DHPP waso$ calculated to be $20 \mathrm{ml} . / \mathrm{min}$.; the uric acid clearance was $6.2 \mathrm{ml} . / \mathrm{min}$. and the endogenous creatinine clearance $136 \mathrm{mg}$. $/ \mathrm{min}$. (Elion and others, 1966a).

After a single oral dose of ${ }^{14} \mathrm{C}$-allopurinol the

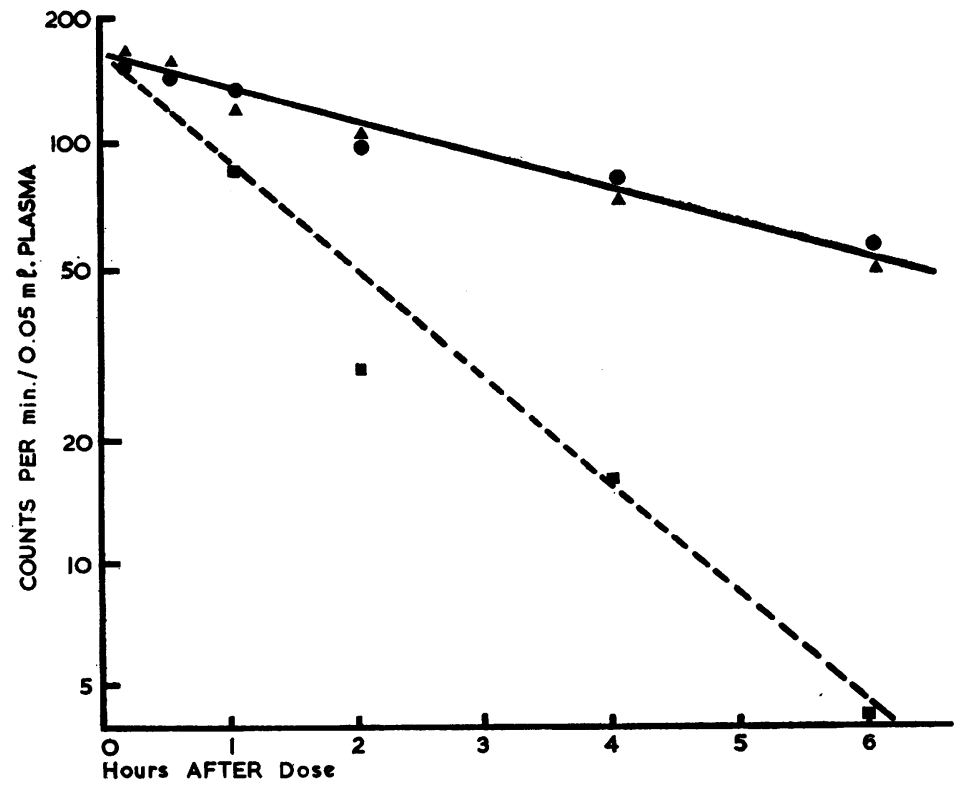

Fig. 4.-Clearance of total ${ }^{10} \mathrm{C}$ and of ${ }^{14} \mathrm{C}$-allopurinol from the plasma of a dog following a single intravenous injection of ${ }^{14} \mathrm{C}$-allopurinol (44.3 mg. $=22 \times 10^{\circ}$ cpm).

, total ${ }^{14} \mathrm{C}$ by direct counting of the plasma;

, total ${ }^{19} \mathrm{C}$ by counting of plasma filtrates, corrected for dilution;

${ }^{14} \mathrm{C}$-allopurinol in plasma, calculated by analysis of plasma filtrates on Dowex-50 $(\mathrm{H}+)$ columns (Elion, 1966). 


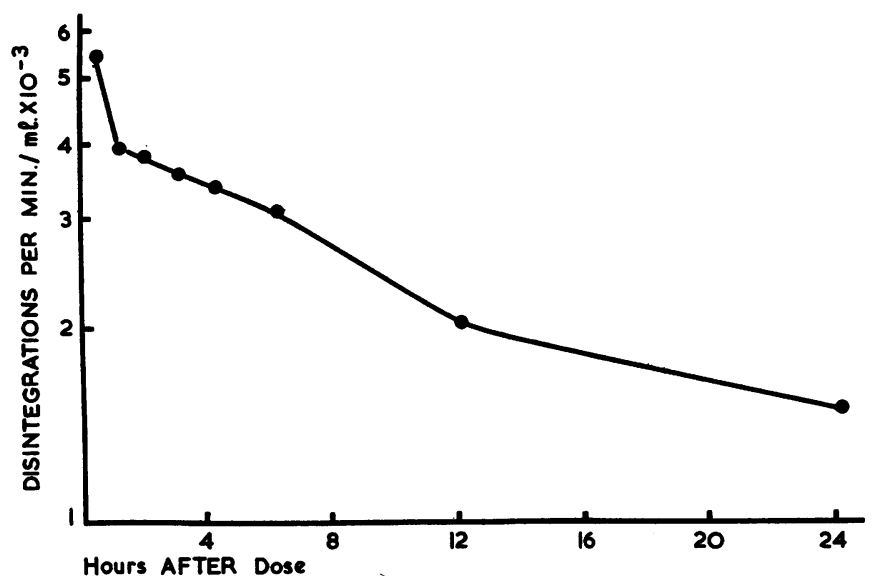

Fig. 5.-Clearance of ${ }^{14} \mathrm{C}$ from the plasma of a patient (Case 1) after a sinzle intravenous dose $(140 \mathrm{mg} .=$ $171 \times 10^{6} \mathrm{dpm}$ ) of $6^{-14} \mathrm{C}$-allopurinol.

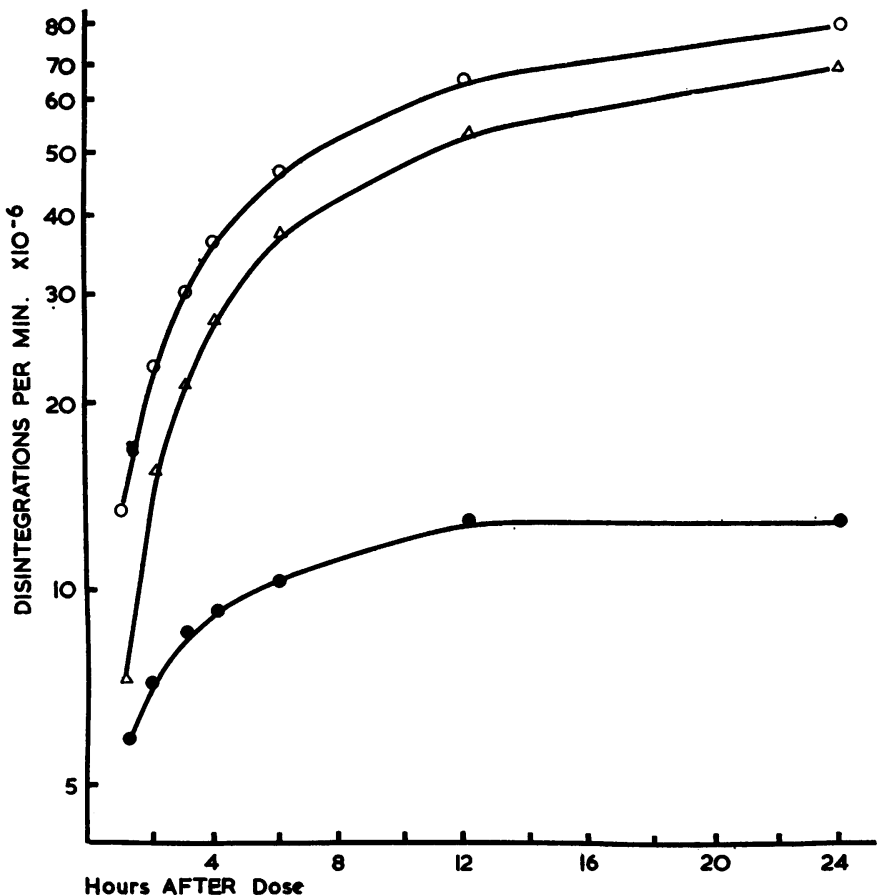

Fig. 6.-Cumulative excretion of radioactive compounds in the urine of Case 1 after a single intravenous dose of ${ }^{14} \mathrm{C}$-allopurinol $\left(140 \mathrm{mg} .=171 \times 10^{\circ} \mathrm{dpm}\right)$. $O$, total; $\triangle$, ${ }^{14} \mathrm{C}$-allo-xanthine , ${ }^{14} \mathrm{C}$-allopurinol.

picture was very much the same as after the intravenous dose, except that it took 1 hour for radioactivity to appear in the plasma and approximately 2 hours to reach a maximum. As before, conversion to DHPP was rapid; no free HPP was found in the urine after 6 hours. The clearance of allo-xanthine in this patient was again slow, corresponding to $15 \mathrm{ml} . / \mathrm{min}$.; the uric acid clearance was $5.3 \mathrm{ml}$./min. Radioactivity equivalent to 20 per cent. of the dose was found in the first 48-hour stool specimen. This probably represents unabsorbed drug, but, by ana- logy with uric acid, it may represent some intestinal 윽 excretion.

The slow clearance rate of allo-xanthine, and the $\frac{7}{2}$ fact that this could not be attributed to protein binding, suggested that allo-xanthine might be \% reabsorbed by the kidney tubule in the same manner $N$ as uric acid. If so, uricosuric agents might be $\mathrm{N}_{\mathrm{J}}$ expected to increase the excretion of allo-xanthine. $O$ Since allopurinol is frequently used in combination with uricosuric drugs, this possibility became of $\frac{0}{\Phi}$ practical as well as theoretical interest. The study $\stackrel{\oplus}{\oplus}$ 
in Case 2 (Fig. 7) was designed to test this hypothesis as well as to investigate the metabolic fate of allopurinol in one who had been on prolonged therapy with the drug. This patient with severe gout had been well controlled for over one year on a regimen of $600 \mathrm{mg}$. allopurinol and $0.5 \mathrm{mg}$. colchicine daily. An oral dose of $70 \mathrm{mg}$. ${ }^{14} \mathrm{C}$-allopurinol was given 24 hours after his last unlabelled dose of the drug, and the unlabelled drug was restarted $(200 \mathrm{mg}$. three times daily) 24 hours later. The appearance of radioactive metabolites in the urine is plotted in Fig. 7. The excretion of free allopurinol persisted somewhat longer than in the patients studied after receiving single doses. This reflects a somewhat greater inhibition of xanthine oxidase resulting from continued therapy, and may be more typical of $\frac{}{\omega}$. patients receiving a therapeutic regimen. Another finding of interest was the presence of a riboside of $\stackrel{\vec{\sim}}{\vec{P}}$ allopurinol which had not been detected by the chromatographic techniques employed earlier. This riboside persisted somewhat longer than the free $\frac{\bar{\rho}}{\bar{\alpha}}$ allopurinol and accounted for about 9 per cent. of $\Phi$ the total dose. Its exact structure is still under $\cong$ investigation. The slow clearance of DHPP was again apparent; 72 hours after the dose of ${ }^{14} \mathrm{C}-\stackrel{\circ}{\circ}$ allopurinol, probenecid was added to the dosage $\overrightarrow{\vec{\omega}}$ regimen ( $3 \mathrm{~g}$. the first day, $2 \mathrm{~g}$. the following day). This led to an increase in the urinary excretion of $\frac{\Omega}{2}$

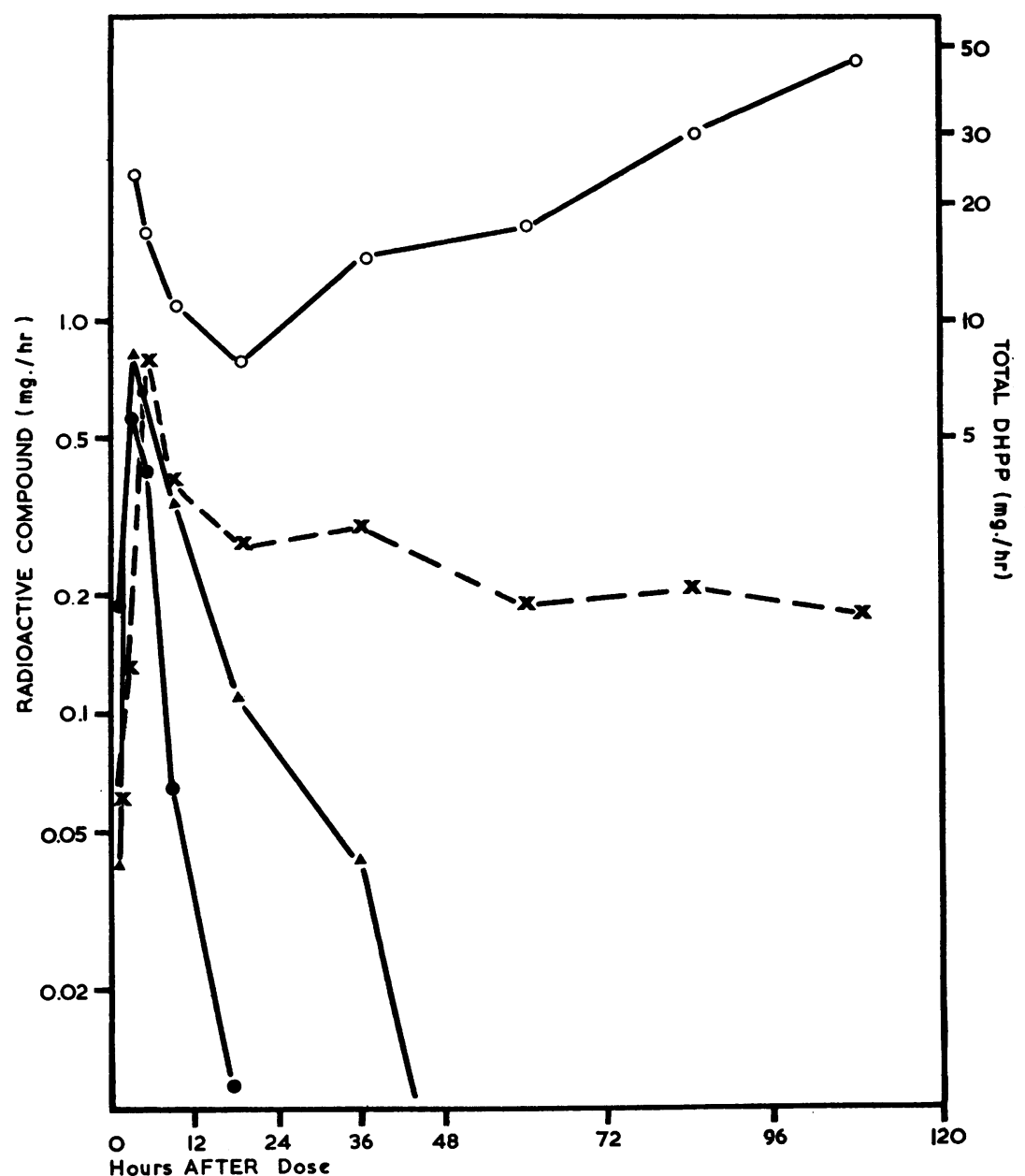

Fig. 7. Excretion of radioactive compounds and of total allo-xanthine in the urine of Case 2 after a single oral dose $\left(70 \mathrm{mg} .=85.5 \times 10^{8} \mathrm{~N}\right.$ dpm) of ${ }^{14} \mathrm{C}$-allopurinol, followed by $600 \mathrm{mg}$./day of non-radioactive allopurinol beginning 24 hrs after the radioactive dose and probenecid C

, ${ }^{14 C}$-allopurinol;

$A,{ }^{11 C}$-allopurinol, as riboside

$\times$, 14 -allo-xanthine;

O, total allo-xanthine.

Urines were collected at $0-2,2-4,4-6,6-12$, and $12-24 \mathrm{hrs}$ after the radioactive dose and daily $24-\mathrm{hr}$ collections were made thereafter. Values for $\mathscr{D}$ excretion per hour are plotted in the middle of each time period. 
${ }^{14} \mathrm{C}$-DHPP and the effect on DHPP excretion was even more marked when the total DHPP (labelled and unlabelled) in the urine was measured. From a total excretion of $420 \mathrm{mg}$. DHPP per day, the amount increased to $720 \mathrm{mg}$. after the first day on probenecid and $1,100 \mathrm{mg}$. after the next day. Uric acid excretion increased from 328 to 765 and 600 mg. per day respectively during this same period.

It is clear that, in so far as renal excretion is concerned, allo-xanthine behaves like an analogue of uric acid rather than xanthine, this in spite of the fact that the $\mathrm{pKa}$ of allo-xanthine $(\mathrm{pKa}=7 \cdot 7)$ is essentially the same as that of xanthine. The oxypurines have been shown to be cleared at rates approximating the glomerular filtration rate when sufficiently high plasma levels are maintained (Goldfinger, Klinenberg, and Seegmiller, 1965). Our studies suggest that the clearance of alloxanthine is only about 15 per cent. of the glomerular filtration rate, or two to three times the clearance of uric acid. Xanthine, allo-xanthine, and uric acid have identical dihydroxypyrimidine moieties; it may be that the structural feature that links alloxanthine and uric acid is the unshared electron pair in the region of the purine- 8 position

$$
(\ddot{\mathrm{N}}: v \cdot \ddot{\mathrm{C}}-\ddot{\mathrm{O}}:)
$$

Whether uricosuric agents might reduce the efficacy of allopurinol by increasing the clearance of allo-xanthine, must remain an open question for the present. In view of the fact that allopurinol is itself a more potent inhibitor of xanthine oxidase than allo-xanthine, it may be that the larger part of the enzyme inhibition is due to unchanged allopurinol. On the other hand, the more constant and elevated levels of allo-xanthine may contribute significantly to the overall effect. Since the clearance values of allo-xanthine appear to parallel those of uric acid, it is possible that patients with poor uric acid clearances will maintain higher serum levels of alloxanthine and require lower doses of allopurinol to maintain effective control.

There are several reports in the literature (Yü and Gutman, 1964; Goldfinger and others, 1965; Klinenberg, Goldfinger, and Seegmiller, 1965) of decreases in oxypurine excretion when uricosuric agents are added to a regimen of allopurinol. Whether this represents only a decreased inhibition due to the more rapid clearance of allo-xanthine, or whether there is also an effect on oxypurine excretion per se remains to be determined. Gjørup and Poulsen (1955) reported that probenecid alone had no effect on the clearance of hypoxanthine and xanthine, but this was at normal plasma levels of oxypurines $(0 \cdot 1-0 \cdot 2 \mathrm{mg}$. per cent.). Recent data in our laboratory on 24-hour oxypurine clearances in patients receiving allopurinol plus uricosuric drugs $\underline{\underline{n}}$ are in good agreement with those of Goldfinger and others (1965) that oxypurine clearances are almost $\overrightarrow{\vec{B}}$ equal to inulin clearances when plasma oxypurine $\frac{0}{\sigma}$ levels are elevated to $0 \cdot 3-0 \cdot 7 \mathrm{mg}$. per cent. by allopurinol therapy. Moreover, even patients with $\frac{\bar{\sigma}}{\bar{\omega}}$ impaired renal function (e.g. $\mathrm{C}_{\text {creatinine }}=40 \mathrm{ml}$./ $\overrightarrow{\widetilde{\sigma}}$ min.) have shown the ability to clear oxypurines at $\cong$ 50-60 per cent. of their creatinine clearance rates and $ळ$ ten to fifteen times their uric acid clearances. In $\overrightarrow{0}$ such patients the substitution of oxypurines for uric acid as the end-product of purine metabolism repre- $\vec{\omega}$ sents a distinct advantage.

Many of the uncertainties mentioned above revolve around the relative effectiveness of allo- in purinol and allo-xanthine in vivo. The usual is experimental models are not able to resolve this $\frac{5}{0}$ problem since lower animals excrete allo-xanthine much more rapidly than man. Firmer data will be $\sigma$ obtained only with studies of allo-xanthine in man. के Some of these have been begun and appear to show that allo-xanthine is an effective xanthine oxidase 을 inhibitor in some patients, but much more will have $\vec{z}$ to be done before the question can be answered.

\section{Summary}

Studies with xanthine oxidase from cow's mile, mouse liver, and human liver show allopurinol to $\overrightarrow{0}$ a competitive inhibitor of xanthine oxidation. To $\mathrm{K}_{\mathrm{i}}$ values vary with the source of enzyme and $p \mathrm{H}$ and are 15 to 200 times lower than the $K_{m}$ for xanthine under the same conditions. The kinetics of the inhibition by allo-xanthine are quite different, since $\overline{0}$ the inhibition becomes progressively stronger with time in the presence of substrate.

Allopurinol is converted in vivo in all animals to $\overrightarrow{\vec{O}}$ allo-xanthine. In lower animals, allopurinol and 3 allo-xanthine are cleared rapidly; in man, allopurinol $\vec{\partial}$ is cleared rapidly but allo-xanthine appears to be reabsorbed by the kidney tubule and is excreted slowly. The slow clearance of allo-xanthine suggests that part of the therapeutic activity of allo- $\frac{1}{3}$ purinol is due to the maintenance of adequate levels of its metabolite. This must be considered when $ᄋ$ uricosuric agents are used in combination with allopurinol since such agents increase the excretion 음 of allo-xanthine.

The metabolic experiments with radioactive allopurinol in man were done in collaboration with Drs. N R. W. Rundles and E. Metz of Duke University School of Medicine. We are indebted to T. J. Taylor, A. Kovensky, F. Benezra, and I. Canellas for their technical $\mathbb{W}_{\mathrm{J}}$ assistance. The helpful advice and encouragement of Dr. George H. Hitchings are gratefully acknowledged. N.B.: Figs 4, 5 and 7 are reproduced by the kind permission of Pergamon Press and by the editors of the Journal of Biochemical (D) Pharmacology. 